\title{
AS REPRESENTAÇÕES SOCIAIS DOS CERRADOS: UM ESTUDO DE CASO NO COLÉGIO ALEXANDRE LEAL COSTA, NO OESTE DA BAHIA ${ }^{1}$
}

\author{
SOCIAL REPRESENTATIONS OF SAVANNAH: ONE CASE STUDY RESEARCH \\ SCHOOL ALEXANDRE LEAL COSTA IN WEST BAHIA
}
REPRESENTACIONES SOCIALES DE LA SABANA: UN ESTÚDIO DE CASO DE LA ESCUELA SECUNDARIA ALEXANDRE LEAL COSTA OESTE BAHÍA

\author{
Valney Dias Rigonato - Universidade Federal da Bahia - Barreiras - Bahia - Brasil \\ rigonatogeo@gmail.com
}

\begin{abstract}
Resumo
Este texto apresenta os resultados das reflexões realizadas a partir das representações sociais - desenhos e escritas - oriundas do Projeto de Intervenção Pedagógica: Pesquisa-Ação (PIP-PA), desenvolvido na disciplina de Estágio Supervisionado em Geografia: "As representações sociais dos Cerrados do oeste da Bahia". A pesquisa foi desenvolvida com os estudantes do $1^{\circ}$ ano do Ensino Médio do Colégio Alexandre Leal Costa, na cidade de Barreiras (BA), em 2011. A metodologia baseou-se nos princípios da Geografia Escolar apoiada pelos procedimentos metodológicos da Pesquisa-Ação, os quais buscam intervir na realidade pesquisada. Além disso, utilizou-se o recurso audiovisual enquanto procedimento metodológico. As representações sociais dos Cerrados, pelos estudantes, se definem em três tipos: cerrados desumanizados, uso e ocupação estereotipados e cenários futuros: desertificação e urbanização.
\end{abstract}

Palavras-chave: representações sociais, cerrados, Geografia Escolar.

\begin{abstract}
This paper presents the results of the reflections made on the basis of social representations - drawings and written - coming from the Pedagogical Intervention Project: Action Research (IPP-PA) developed in the discipline of Supervised Internship in Geography, "Social representations of the West Cerrados Bahia. "The research was conducted with students in 1st year high school Alexandre Leal Costa in the town of Barreiras (BA), in 2011. The methodology was based on the principles of Geography School supported by the methodological procedures of Action-Research which seek to intervene in the reality studied. Also, used the audiovisual resource as a methodological procedure. Social representations of Savannah by the students are defined in three types: Cerrados dehumanized, use and occupation stereotyped and future scenarios: desertification and urbanization. Keywords: social representations, cerrados, Geography School.
\end{abstract}

\section{Resumen}

Este artículo presenta los resultados de las reflexiones hechas sobre la base de las representaciones sociales, dibujos y escritos - que viene del Proyecto de Intervención Pedagógica: Investigación-Acción (IPP-PA), desarrollado en la disciplina de prácticas supervisadas en Geografía, "Representaciones sociales de la Cerrados Oeste Bahía ". La investigación se realizó con los alumnos en $1^{\circ}$ año de la escuela secundaria Alexandre Leal Costa en la ciudad de Barreiras (BA), en el año 2011. La metodología se basó en los principios de la Escuela de Geografía apoyados por los procedimientos metodológicos de la investigación-acción que tratan de intervenir en la realidad estudiada. Además, se emplearon el atractivo visual de audio como un procedimento metodológico. Las representaciones sociales de los estudiantes de la sabana se definen en tres tipos: Cerrados deshumanizados, el uso y la ocupación estereotipados y escenarios futuro: la desertificación y la urbanización. Palabras clave: representaciones sociales, cerrados, Escuela Geografía. 
Introdução

Antes de tecer minhas considerações sobre as representações dos Cerrados, é preciso esclarecer ao leitor que optarei neste texto pelo uso do termo no plural. Tal escolha refere-se ao esforço de (des)construir a singularidade do discurso científico moderno, que usualmente caracteriza as porções naturais do planeta Terra de forma homogênea e generalista. Utiliza-se, então, o termo Cerrados ${ }^{2}$ na perspectiva de valorização geoecológica, social, cultural e política desse domínio, assim como entende Aziz Nacib Ab'Saber (2003).

Nas últimas décadas houve uma revalorização das áreas de Cerrados. Os Cerrados passam de terras inóspitas para terras de celeiro produtivo. Para isso, ocorreram o emprego de novas tecnologias na produção agrícola e o processo de urbanização e industrialização (agronegócio). Houve metamorfoses tanto nos elementos ecológicos dos Cerrados como no estilo e no modo de vida das populações tradicionais, pequenos agricultores, quilombolas, posseiros e outros grupos.

Os Cerrados baianos foram simplificados em prol do agronegócio. ${ }^{3}$ Áreas ricas em biodiversidade. Biodiversidade pouco conhecida pela ciência moderna. Conhecimento que poderia ter agregado valor sem a necessidade do desmatamento e das queimadas para o desenvolvimento da chamada "modernização da agricultura". O Ministério do Meio Ambiente (Brasil, 2012) classificou os vinte municípios com os maiores índices de desmatamento das áreas de Cerrado, no período de 2002 a 2008. Destes, seis municípios do Estado da Bahia (1 $1^{\circ}$ lugar - Formosa do Rio Preto; $2^{\circ}$ lugar - São Desidério; $3^{\circ}$ - Correntina; $9^{\circ}$ - Jaborandi; $14^{\circ}$ - Barreiras; e $17^{\circ}$ Riachão das Neves) destacam-se com os maiores índices de desmatamento das áreas de Cerrados (Figura 1).

Como se vê, o munícipio de Barreiras, no qual a pesquisa foi desenvolvida, encontra-se com muitas áreas suprimidas. Cabe destacar que desde o século XIX os primeiros ocupantes desse munícipio já desenvolviam a pecuária extensiva e agricultura de subsistência. Além disso, o município teve o leite de mangaba como um dos principais produtos econômicos no início do século passado. A partir da década de 1960, foi palco da especulação de terras, as quais, com incentivo de políticas públicas, foram ocupadas, desmatadas para o plantio de monoculturas de soja, milho, arroz e, mais recentemente, de algodão, tornando-se palco da expansão 
da fronteira agrícola e, mormente, de todas as atividades do agronegócio. Essa ocupação vem provocando a perda significativa da biodiversidade do munícipio e dos demais munícipios do Oeste da Bahia.

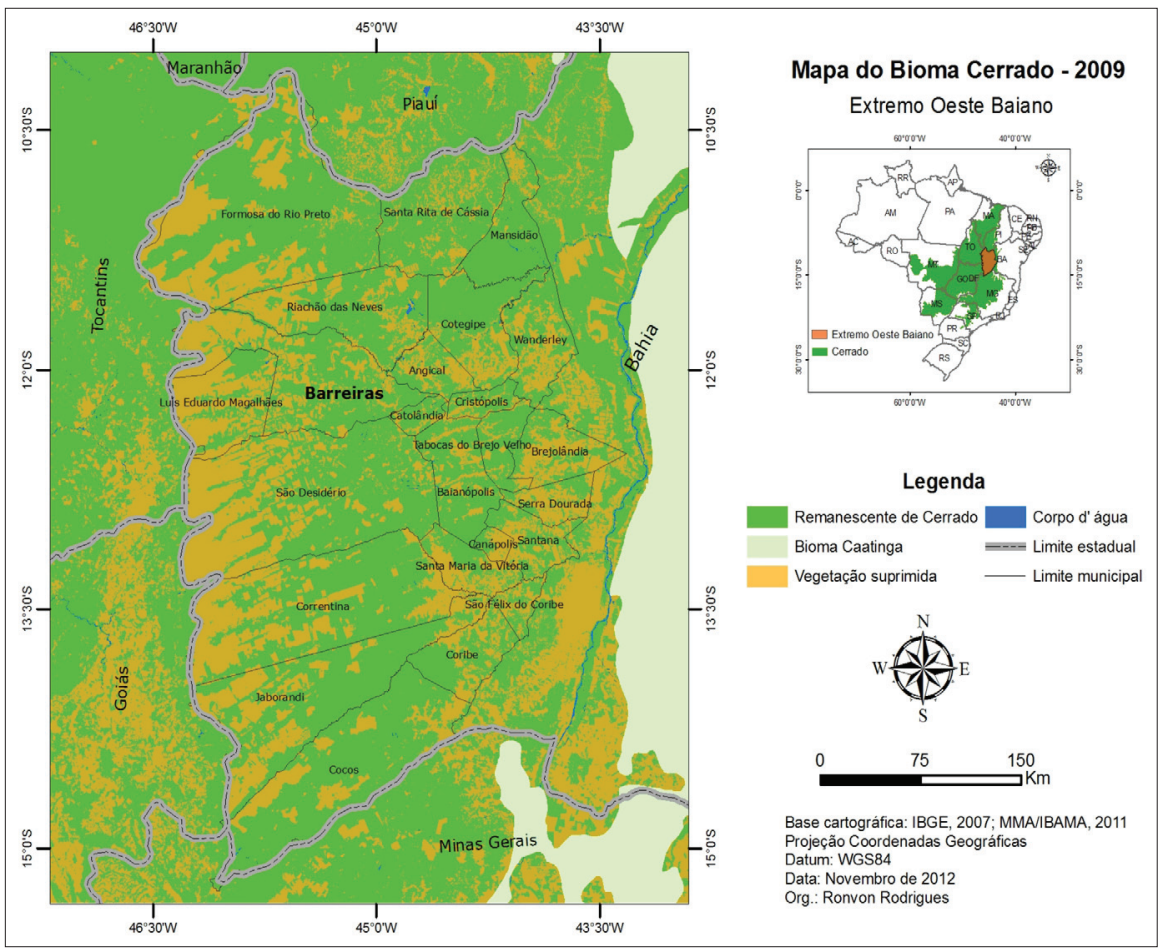

Figura 1 - Mapa do bioma Cerrado - Extremo Oeste baiano (2009)

Para Albagli (1998, p.66), a perda da biodiversidade tem correspondência com a significativa perda da diversidade sociocultural. Já na abordagem de Haesbaert (1995), esse fenômeno nos cerrados nordestinos se realiza pela "reterritorialização gaúcha" e "des-territorialização" das populações locais das áreas de Cerrados. Ebulições que possivelmente metamorfosearam as representações sociais dos habitantes desse município, sobretudo dos estudantes.

Com isso, tanto as universidades como as escolas reproduziram representações sociais construídas a partir do "mito da neutralidade científica" e da "natureza infinita" (Diegues, 1996). Esse último mito foi 
divulgado pelos livros didáticos de Geografia e de Ciências, nos quais a natureza (Cerrados) e seus elementos do meio ecológico (como água, solo, vegetação) foram considerados infinitos. Nesse sentido, são usados e ocupados sem preocupação de preservação para as gerações do presente e para as futuras gerações. Cabe aqui ressaltar que na Conferência Internacional Rio 92 tais representações sociais foram debatidas à luz da educação ambiental no território brasileiro.

A metodologia utilizada nesta pesquisa foi estruturada a partir dos princípios teóricos da Geografia Escolar e da metodologia de pesquisa-ação. Para Thiollent (2008), na pesquisa-ação os pesquisadores desempenham um papel ativo no equacionamento dos problemas encontrados, no acompanhamento e na avaliação das ações desencadeadas em função dos problemas. Sem dúvida, a pesquisa-ação exige uma relação participativa entre pesquisadores e pessoas da situação investigada. Os problemas de aceitação dos pesquisadores no meio pesquisado precisam ser resolvidos no decurso da pesquisa. No caso deste trabalho, durante o Estágio Supervisionado. Entretanto, só a participação do pesquisador não qualifica a especificidade da pesquisa-ação, que consiste em organizar a investigação em torno da concepção, do desenrolar e da avaliação de uma ação planejada (Thiollent, 2008, p. 15).

Com base nesses princípios, organizou-se o desenvolvimento do Estágio Supervisionado em Geografia, com o Projeto de Intervenção Pedagógica: Pesquisa-Ação (PIP-PA), no qual se buscou - nas ações e na relação entre investigador e investigado - a identificação e (re)valorização das representações sociais dos Cerrados pelos protagonistas do espaço escolar em questão, em especial, os estudantes. Nesse ensejo, cabe apontar que o universo pesquisado somou 73 estudantes - antes, durante e depois do desenvolvimento do Projeto de Intervenção Pedagógica: Pesquisa-Ação (PIP-PA), e durante o desenvolvimento da disciplina "Didática e Práxis Pedagógica: Estágio IV”, enquanto atividade curricular de formação do curso de licenciatura em Geografia do Instituto de Ciências Ambientais e Desenvolvimento Sustentável - ICADS/UFBA, sob minha orientação. Cabe aqui frisar que a maioria desses estudantes (futuros professores de Geografia) são oriundos de famílias com baixo poder aquisitivo, filhos de camponeses desapropriados, afrodescendentes, que têm o curso como uma das únicas oportunidades de transformação de suas condições de vida. 
Utilizou-se também bibliografia específica sobre as representações sociais, tais como: Moscovici (2003), Lefebvre (2006), Kozel (2008), Moreira (2010) - que discutem as representações sociais no campo epistemológico utilizadas na leitura geográfica. Já no plano mais ontológico, buscou-se dialogar com Cavalcanti (1998), Almeida (2003, 2005, 2008), Serpa (2007), Moreira (2010), entre outros - que discutem as representações sociais tanto relacionadas com os cerrados, quanto com a área do ensino de Geografia. Entretanto, são poucas as pesquisas que buscaram e/ ou buscam identificar as representações sociais dos estudantes nas áreas de fronteira do agronegócio, em áreas dos Cerrados baianos, sobretudo aquelas que procuram discutir as perspectivas futuras do processo de uso e ocupação dos Cerrados.

Dessa forma, acredita-se que essa pesquisa é significativa pela contextualização - no espaço escolar - das transformações do processo de uso e ocupação das áreas de Cerrados. Significativa também para debater, à luz da ciência geográfica escolar contemporânea, as representações sociais dos estudantes sobre a relação espaço e tempo - passado, presente e futuro dos Cerrados baianos, no oeste da Bahia, neste início do século XXI.

\section{As representações sociais na Geografia Escolar}

Nas últimas décadas, as representações sociais são pesquisadas no campo simbólico e subjetivo da ciência contemporânea. Essa tendência compartilha, em parte, com mudanças epistemológicas inseridas na ciência geográfica, sobretudo aquelas ligadas à geografia humanística. Lefebvre (2006), em seu livro A produção do espaço, colabora ao dizer que as representações sociais são construídas na própria produção do espaço, e distingue a diferença entre "espaço de representação" e "representação do espaço". Além disso, assegura que "as representações do espaço teriam assim um alcance considerável e uma influência específica na produção do espaço" (2006, p. 71).

Tal abordagem pode proporcionar aos profissionais da Geografia Escolar oportunidade de contextualizar a produção do espaço nas áreas de Cerrados. E essa disciplina pode contextualizar as práticas espaciais na escola, para que os seus protagonistas, sobretudo os estudantes, possam conceber o complexo jogo de relações sociais e espaciais vividas nos diversos lugares geográficos. E que as representações sociais dos Cerrados 
possam revelar não só as características do espaço absoluto, mas revelar o jogo de simbolismos, de ideologias, de poder real e imaginário que constituem esses espaços.

Como se vê, a base de sustentação das representações sociais está alocada na superestrutura e, mormente, de forma direta ou indiretamente, com as forças produtivas do espaço geográfico nos Cerrados brasileiros. Entretanto, as representações sociais das coisas e de alguém realizam-se na infraestrutura, no amálgama das relações sociais, da produção do espaço vivido pelas pessoas e grupos.

Nesse contexto, a escola é compreendida enquanto simulacro do espaço e tempo vivido no processo de (re)produção do espaço geográfico dos Cerrados baianos. Para Kozel (2002), essa vertente de análise entende que as representações sociais envolvem

o comportamento humano, tendo como premissa que este é adquirido por meio de experiências (temporal, espacial e social), existindo uma relação direta e indireta entre essas representações e as ações humanas, ou seja, entre as representações e o imaginário, revolucionando a gênese do conhecimento, permitindo compreender a diversidade inerente às práticas sociais, às mentalidades e aos vividos. (Kozel, 2002, p. 22)

Como bem aponta a autora, as representações sociais podem auxiliar não só para elucidar o mundo vivido pelos estudantes, mas também para identificar as possibilidades imaginárias dentro das práticas sociais vividas. Assim, é importante que os estudantes percebam que seu espaço vivido é repleto de interesses e significados, os quais são revelados na produção do espaço geográfico dos Cerrados e, mormente, em suas representações sociais.

A escrita, o discurso e os desenhos são formas de expressão das representações sociais dos estudantes no espaço escolar. O professor de Geografia pode utilizá-las para o desenvolvimento de habilidades e competências do conhecimento escolar. Mas para isso é preciso, no mínimo, contextualizar o processo de uso e ocupação dos Cerrados, os grupos sociais e a diversidade cultural que os constituem.

Straforini (2004) sintetiza ao afirmar:

O papel da Educação e, dentro dessa, o do ensino de Geografia, é trazer à tona as condições necessárias para a evidenciação das contradições da sociedade a partir do espaço, para que no seu entendi- 
mento e esclarecimento possa surgir um inconformismo e, a partir daí, uma outra possibilidade para a condição da existência humana. (Straforini, 2004, p. 57)

Tais reflexões apontam para além do caráter formal do currículo escolar, colocando-nos a importância do contexto social no processo de ensino-aprendizagem da Geografia Escolar contemporânea. Nessa perspectiva, as representações sociais dos estudantes são partes constituintes dos conteúdos geográficos a serem ensinados, os quais podem ser selecionados com objetivos sociopolíticos definidos a partir da contextualização do espaço geográfico vivido e percebido nos Cerrados baianos.

Contudo, as análises mais quantitativas dos dados da pesquisa demonstram que 55\% ainda consideram os Cerrados como meio ambiente inóspito. Menos de 5\% representaram a presença dos seres humanos no passado dos Cerrados. Os outros 40\% revelam estereótipos em relação ao processo de uso e ocupação das áreas de Cerrados, inclusive com reprodução de conceitos divulgados pela mídia de massa. Com base nesse diagnóstico, procederei à discussão dos três grupos de representações sociais identificadas nos desenhos-textos dos estudantes pesquisados: cerrados desumanizados; uso e ocupação estereotipados; e cenários futuros: desertificação e urbanização.

\section{Cerrados desumanizados}

A concepção de “Cerrados desumanizados" interliga-se com a visão de desnaturização (Moreira, 2010). Nessa concepção, as representações sociais dos Cerrados demonstram a visão inóspita dessas áreas, ainda presente no imaginário social das populações que (sobre)vivem nas/das franjas de Cerrados. ${ }^{4}$ Uma imagem que socialmente é muito denominada de sertão, ${ }^{5}$ destacada desde os viajantes naturalistas (Corrêa, 2001). Dessas viagens, germinam representações sociais progressistas que objetivaram a intervenção e as ocupações dos chamados vazios demográficos brasileiros. Além disso, essas representações sociais foram revalorizadas no processo de modernização do território brasileiro, com base nos mitos da modernidade: o mito da natureza infinita; o mito do progresso e do crescimento ilimitado; o mito da igualdade socioeconômica e do sucesso garantido nos grandes centros urbanos; o mito da neutralidade e da superioridade da ciência e da tecnologia (Duarte, 2002, p. 18). Tais mitos 
propagaram-se nas áreas dos Cerrados brasileiros e motivaram as diversas ações que metamorfosearam os modos de vida das populações desse meio. Concomitantemente, ocorreu também a ampliação de oportunidades e possibilidades de desenvolvimento no processo de ensino e aprendizagem escolar. No entanto, ainda não se conseguiu eliminar essas representações do imaginário social vivido pelos estudantes no município de Barreiras, como se observa na Figura 2:

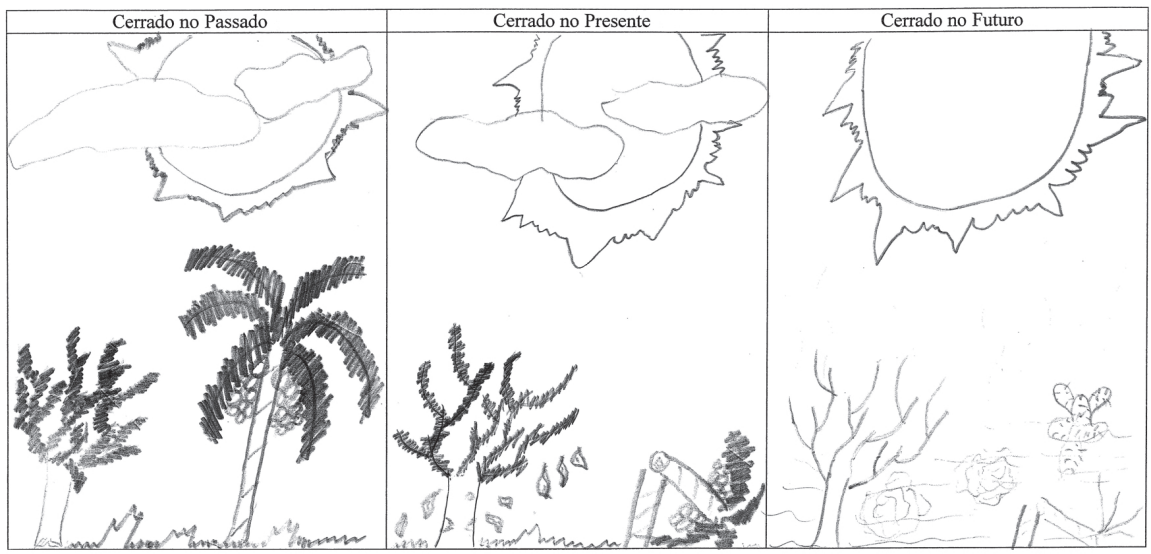

Figura 2 - Cerrados naturais, sem presença do ser humano Fonte: Oliveira, 2011

Entretanto, como já foi apontado, houve um pequeno grupo de estudantes que representou a presença dos seres humanos no passado, como se vê na Figura 3.

Diante disso, cabe salientar: uma vez que a visão de Cerrados inóspitos e de paraíso natural ainda é muito presente nas representações dos estudantes do ensino médio, qual o papel da escola e do currículo de Geografia na construção das representações sobre o que significam realmente os Cerrados e o seu processo de uso e ocupação no oeste da Bahia? Cabe lembrar que a pesquisa foi desenvolvida na cidade de Barreiras, situada nas áreas de Cerrados baianos, que passaram por diversas ebulições para atender à dinâmica de modernização da agricultura. 

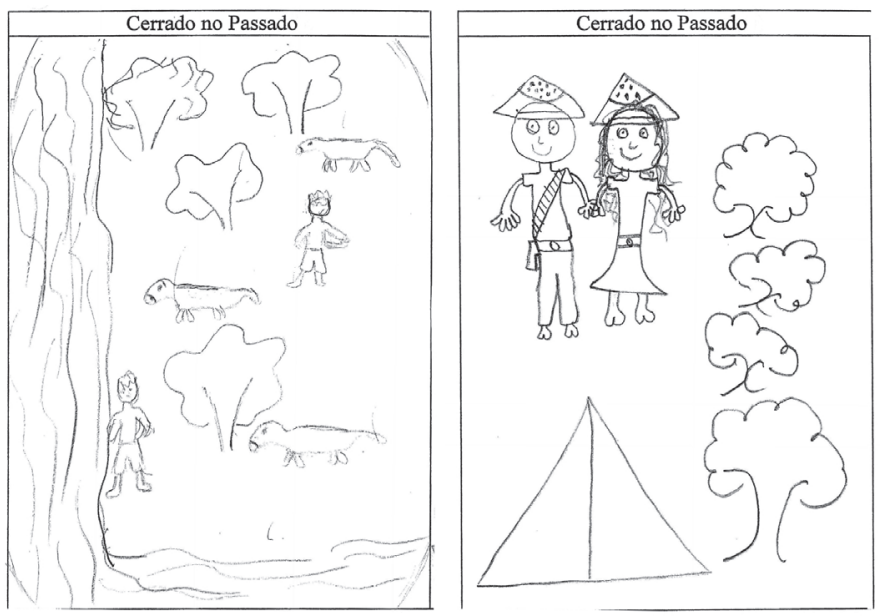

Figura 3 - Os poucos seres humanos nos Cerrados (no passado) Fonte: Oliveira, 2011

Outro aspecto identificado foi a ausência quase total da fauna. Essa informação demonstra o pouco conhecimento da rica biodiversidade da região. Revela o conhecimento apenas dos aspectos visuais das fitofisionomias dos Cerrados. As representações revelam o silêncio visual em relação à diversidade geoecológica, apontada no início deste texto. Em síntese, pode-se afirmar que esses aspectos identificados mostraram o pouco conhecimento dos estudantes sobre a biodiversidade dos Cerrados e, mormente, demonstraram a dificuldade da escola em contextualizar a vida desses estudantes com a realidade vivida nas áreas de Cerrados.

Em relação à análise das representações/desenhos, percebe-se, de forma geral, que muitos buscaram representar os aspectos afetivos, idílicos, pobres e belos das paisagens dos Cerrados naturais. Desse grupo de estudantes, menos de 10\% evidenciaram a simplificação dos Cerrados pelo desmatamento. Mesmo nessas representações a presença humana e dos animais foram inexistentes. Tal fato e a pouca valorização dos seres humanos nos Cerrados do passado reforçam o aspecto de desumanização dos Cerrados, tanto difundido por meio do "mito da natureza intocada e infinita” presente na sociedade ocidental.

Além de representarem os Cerrados desumanizados, os mesmos foram representados sem sua flora. Outro aspecto das fitofisionomias de 
Cerrados foi a presença de representações das espécies arbóreas, possivelmente uma tentativa de demonstrar a importância das "madeiras de lei" que outrora foram valorizadas para a construção de infraestrutura de casas, construção de cercas, pontes, entre outras utilizações. Nota-se o desaparecimento dos aspectos naturais dos Cerrados, mas também notam-se as tradições, os modos de vida e os costumes das pessoas que habitavam e habitam as áreas dos Cerrados baianos, conforme Figura 3.

\section{Uso e ocupação estereotipados}

Em relação ao processo de uso e ocupação da biodiversidade dos Cerrados, verificaram-se representações sociais estereotipadas dos estudantes, devido a seu pouco conhecimento acerca desses usos/ocupações. Tal estereótipo se constitui na lógica dual e conflituosa dos "seres humanos versus Cerrados".

Cabe destacar que esses estudantes, em sua maioria, são filhos de famílias que migraram para o espaço urbano de Barreiras (BA), e que sofreram com "[...] a ruptura do saber e conhecimento acumulado em sua vivência com a natureza” (Almeida, 2008, p. 331). Todavia, sobrevivem em áreas de expansão da fronteira agrícola brasileira, que é marcada pela inserção do agronegócio com diversas alterações ambientais. Essa realidade empírica contribuiu para a formação de representações sociais dos Cerrados estereotipadas em relação ao uso e ocupação vigentes.

Para Massey (2008), "o modo como imaginamos o espaço tem seu efeito". A autora assegura também que a imaginação espacial "reduz coexistências simultâneas a um lugar na fila da história”. Daí a importância de se refletir, a partir das representações sociais, sobre quais são as coexistências representativas do processo de uso e ocupação das áreas de Cerrados.

Observe-se a Figura 4 e o texto/resposta a seguir: 


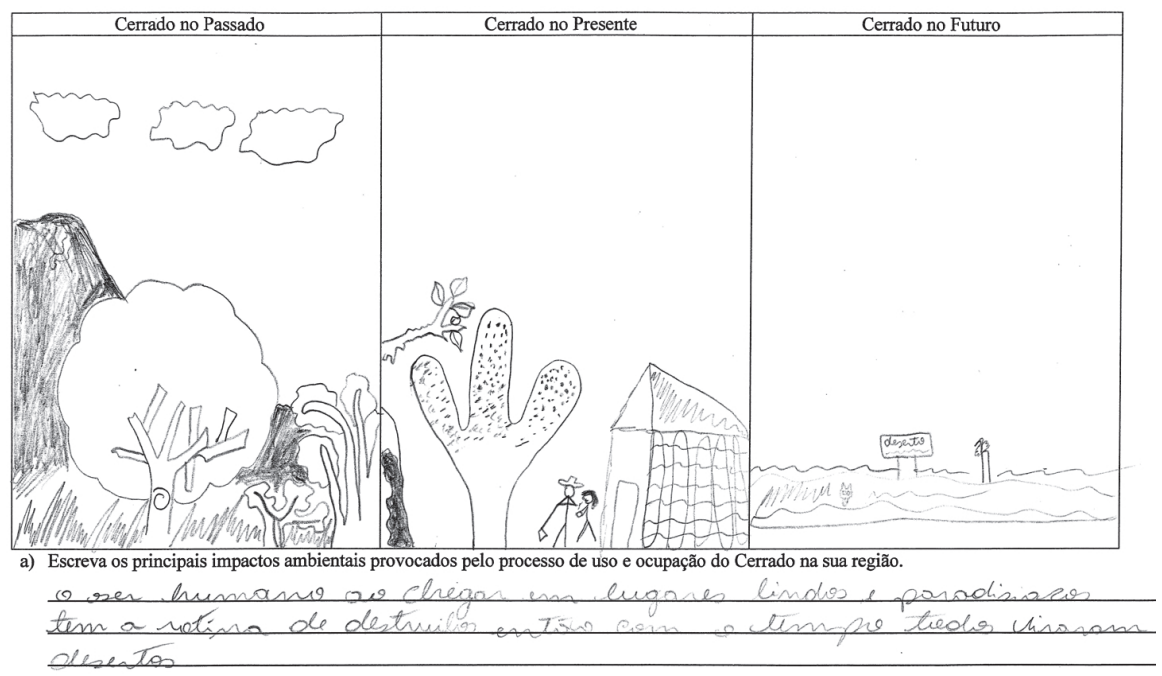

Figura 4

Fonte: Oliveira, 2011

Resposta escrita:

O ser humano, ao chegar a lugares lindos e paradisíacos, tem a rotina de destruí-los. Então, com o tempo, todos viraram desertos. Estudante E. V.

Como se vê na figura e no texto acima, as paisagens, ao longo do tempo, foram sendo simplificadas. A espécie de cacto representada na figura demonstra a sensibilidade dos estudantes em relação às características paisagísticas da faixa de transição dos Cerrados para Caatinga, onde se encontram. Observa-se também a influência do discurso midiático ambientalista internalizado pelos estudantes, uma vez que suas representações demonstram pouco conhecimento geográfico dos usos - mineração, agricultura de subsistência, pecuária extensiva e o próprio agronegócio.

O imutável das representações analisadas foi a tendência marcante de ciclo linear de simplificação, tanto da biodiversidade como da heterogeneidade das paisagens culturais nas áreas de Cerrados. Assim, demonstram o contraponto entre as representações vividas e as hegemônicas. Daí, emerge o papel pedagógico da escola de reconstruir possibilidades para se renegarem as representações inóspitas do passado, de contextualizar as vividas do presente e apontar as diversas possibilidades para o futuro, inclusive alternativas de outros modelos de uso e ocupação dos Cerrados, 
potencializando outro imaginário geográfico sobre o processo de uso e ocupação dos Cerrados baianos.

Em síntese, possivelmente a falta de formação de conceitos relacionados ao processo de uso e ocupação dessas áreas, aliada ao papel da comunicação de massa, contribuíram para consolidar representações estereotipadas: Cerrados inóspitos e cênicos de futuro incerto.

\section{Cenários futuros: desertificação e urbanização}

A construção de cenários futuros no processo de ensino e aprendizagem de Geografia é ainda pouco utilizada no território brasileiro. Tal evidência pode correlacionar a nossa "indolência epistemológica" (Santos, 2000) e a visão estratégica do saber geográfico no espaço escolar. Nesse sentido, Castrogiovanni (2011, p. 175) aponta a importância de se reconstruir o saber geográfico a partir da tríade: informação, conhecimento e sabedoria. Essa última coloca, inclusive, a tomada de decisão em relação aos cenários futuros da produção do espaço geográfico nas áreas de Cerrados. Já para Serpa (2008, p. 66), “uma Geografia assim deve estar atenta às experiências do fazer e do agir solidários, às experiências de autonomia e aos seus desdobramentos futuros".

A análise dos desenhos e dos textos/respostas dos estudantes indica duas tendências atribuídas aos cenários futuros dos Cerrados: desertificação e urbanização. Tais ocorrências podem ser visualizadas na Figura 5 e no texto/resposta a seguir, e nas Figuras 3 e 4 anteriores.

Por um lado, essas representações sociais dos estudantes apontam que estão atentos às transformações do espaço vivido e cotidiano, uma vez que moram em áreas de forte devastação dos Cerrados e intenso processo de urbanização das cidades, a exemplo de Barreiras, Luís Eduardo Magalhães e São Desidério, no Estado da Bahia. Por outro lado, como já foi mencionado, as representações sociais demonstram a incapacidade da instituição escolar de formar conceitos, diante dos rótulos estereotipados ventilados pela comunicação de massa, uma vez que também houve a ausência de comentários escritos sobre a arenização, fenômeno natural mais adequado para as áreas de Cerrados. A recorrência do discurso de desertificação no processo de uso e ocupação dessas áreas revela a influência da mídia televisiva de massa. 


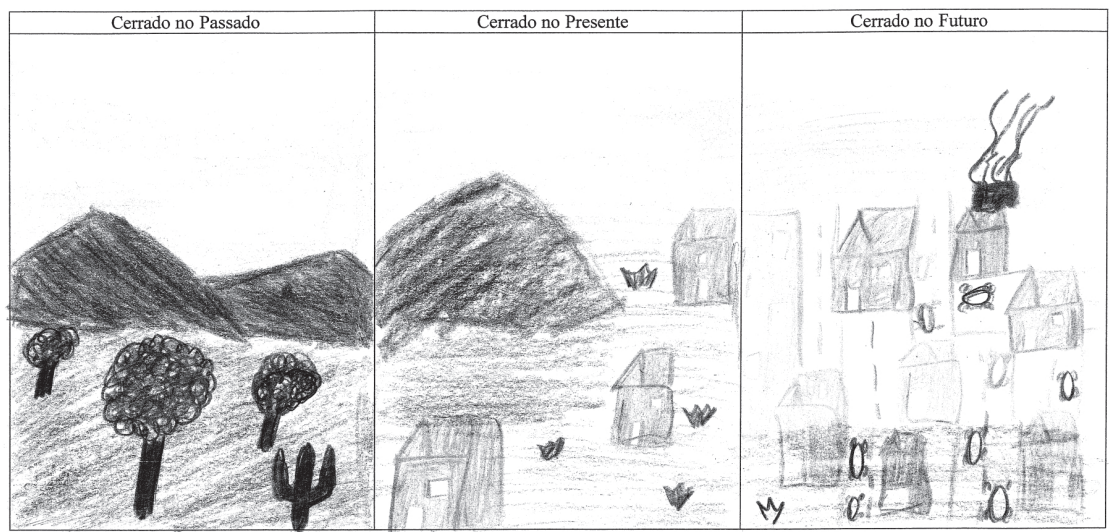

a) Escreva os principais impactos ambientais provocados pelo processo de uso e ocupação do Cerrado na sua região.

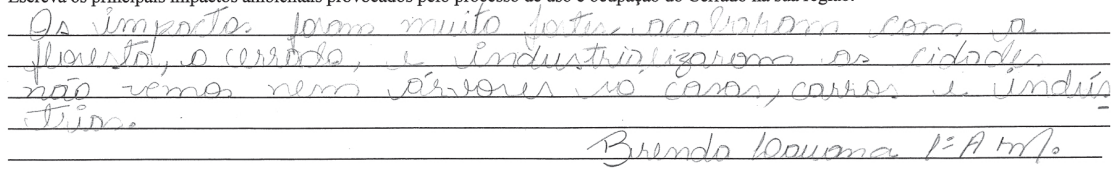

Figura 5 - Cerrado urbanizado no futuro

Fonte: Oliveira, 2011

Resposta escrita:

Os impactos foram muito fortes. Acabaram com a floresta, o cerrado, e industrializaram as cidades. Não vemos nem árvores, só casas, carros e indústrias.

Cabe aqui frisar que em veredas e áreas de Cerrados baianos há experiências de agroextrativismo desenvolvidas pelas populações tradicionais, populações ribeirinhas e pequenos agricultores, de forma mais sustentável. Utilizam raízes, fibras, frutos e capins, inclusive o capim dourado, gerando emprego e renda no campo. Entretanto, esses cenários não foram mencionados, sobretudo pelos estudantes da zona rural do município de Barreiras que compõem o grupo da pesquisa.

Diante disso, destaca-se a importância de contextualizar a vida dos estudantes nos espaços escolares, principalmente no ensino da Geografia Escolar. Esse caminho pedagógico pode abrir uma janela para revelar outras paisagens, outras formas de uso e ocupação dos ambientes vividos. Para isso, a escola precisa assumir o papel de protagonista a partir dos princípios lógicos da Geografia: "localização, extensão, densidade, conexão, delimitação e escala” (Moreira, 2010).

Nessa mesma perspectiva, Serpa (2008) assevera: 
Imaginar é abstrair a realidade para a ela voltar após sonhar. Sonhar uma nova realidade para além do presente e do passado requer também coragem para imaginar um outro mundo, outros modos de vida possíveis, para além da sociedade de consumo e da mercadoria. (Serpa, 2008, p. 65)

Acredita-se, portanto, que os profissionais da educação, principalmente os da área de Geografia, precisam promover um ensino que propicie oportunidades, que alimente novas esperanças e amplie as possibilidades de viver, de imaginar e de criar cenários do espaço vivido dos estudantes. Cavalcanti (2011), ao refletir sobre o ensino de Geografia na sociedade contemporânea, assevera que

nesse cenário pode-se incluir um projeto de ensino de Geografia articulado a um projeto de sociedade de cunho mais humanista, que busque a formação cidadã, pautada na justiça social, nas diferentes escalas geográficas e nas diferentes dimensões da vida humana. (Cavalcanti, 2011, p. 94)

Essas reflexões estão interligadas com as infinitas possibilidades teórico-didáticas de construção do saber geográfico no espaço escolar contemporâneo. Uma construção que valorize as perspectivas objetivas e subjetivas na elaboração de representações sociais e, se possível, na (re) construção de cenários futuros com mais autonomia no fazer social em relação às velhas e novas territorialidades nas áreas de Cerrados.

0 papel do audiovisual no ensino de Geografia com as representações sociais dos Cerrados

Como se pôde observar nas discussões anteriores, os estudantes do ensino médio da cidade de Barreiras externalizaram representações sociais que possuem influência da comunicação de massa. Muitas, inclusive, representações sociais etnocêntricas, com reprodução de paisagens estereotipadas, com presença apenas das fitofisionomias e de um espaço rural idílico. Os estudantes demonstraram pouco conhecimento da vivência nas áreas dos Cerrados baianos.

No entanto, o propósito aqui não é aprofundar esse debate, e sim destacar a importância da utilização do documentário referenciado no subtítulo acima, construído com o objetivo de contextualizar o processo de uso e ocupação dos Cerrados e sua importância no território brasileiro. 
Esse material foi produzido pela Universidade Federal de Goiás, com patrocínio da Sociedade Brasileira para o Progresso da Ciência - SBPC. Foi o instrumento didático-pedagógico utilizado para desenvolver a interatividade dos estudantes com o conteúdo.

Durante a exibição do documentário, os estudantes demonstraram envolvimento e participação nas discussões. Assim, pode-se afirmar que tanto o documentário, como as aulas e as explicações, foram importantes para o início da reformulação dos conceitos relacionados aos Cerrados. Notou-se que houve, no segundo momento, escritas mais contextualizadas com o processo de uso e ocupação das áreas de Cerrados, nos três estágios - passado, presente e futuro -, como demonstram os textos/respostas dos estudantes, a seguir:

Resposta 1 - estudante A. L.

"A vegetação do cerrado está associada ao clima da região, às semelhanças em várias regiões da terra de tipos específicos; caracterizam diversos tipos de clima."

Resposta 2 - estudante A. L.

"Cerrado é um tipo de bioma brasileiro localizado principalmente na região Centro-Oeste. Assim como a Amazônia, serve para o equilíbrio do planeta, diminui a poluição do ar e garante um emprego sustentável para todas as famílias que vivem ao redor, ou seja, no Cerrado é extremamente sustentável."

Resposta 1 - estudante J. C.

"Um desses impactos é a desertificação da área. No lugar de árvores constroem casas, com isso vindo a desabitar os animais que faziam moradia daquele local, causando a morte e mudança de muitos animais que ocupavam aquela área. Além da ocupação desordenada, tem o fato das queimadas, que mais destroem o Cerrado brasileiro, ainda mais no período de secas.”

Resposta 2 - estudante J. C.

"O Cerrado é um lugar onde se concentra um rico ecossistema, onde são encontradas várias espécies de animais e vegetações diversificadas, como ipê, pequi, caju, entre outras da região [...]. Essas plantas e animais ajudam a manter o equilíbrio do planeta.”

Como se vê acima, o uso do audiovisual auxiliou na construção das respostas, individuais e coletivas, conforme a metodologia da pesquisa-ação. Houve, principalmente, a ampliação da capacidade argumentativa dos estudantes. Notou-se também a valorização da biodiversidade dos 
Cerrados, uma vez que os estudantes até apontam algumas espécies, das quais no primeiro contato revelaram pouco conhecimento. Outro fator preponderante foi a inclusão dos impactos ambientais mais contextualizados com a realidade vivida.

O uso de documentários contextualizados pode auxiliar no processo de ensino e aprendizagem em Geografia Escolar, sobretudo no estudo das representações sociais. No entanto, os "geógrafos-educadores" devem "saber como utilizá-las sem se deixar usar por elas" (Bourdieu, 2000). No caso específico dos Cerrados, os "geógrafos-educadores" precisam romper com a legitimação de paisagens estereotipadas, com a inautenticidade das fitofisionomias, para a (re)construção de representações sociais menos etnocêntricas, principalmente do processo de uso e ocupação dessas áreas.

Para tanto, é significativa a valorização dos saberes populares, da biodiversidade nativa e da cultura local, em oposição às representações sociais singulares. Espera-se que se instituam representações sociais plurais que possam fortalecer a diversidade cultural e social dos Cerrados baianos.

\section{Considerações finais}

O presente texto buscou caminhos para discutir e contextualizar as representações sociais dos principais protagonistas do espaço escolar os estudantes - no processo de ensino e aprendizagem em Geografia, em relação às ebulições espaciais nos Cerrados brasileiros. Assim, buscou-se valorizar algumas formas de externalização - desenhos e textos - enquanto representações sociais dos estudantes, enquanto recurso didático para aproximação e (re) construção do saber geográfico escolar, nas áreas de fronteiras do agronegócio nos Cerrados. Além disso, procurou-se valorizar o documentário Cerrado: afinal o que é? E para que serve o Cerrado?, enquanto instrumento audiovisual didático-pedagógico para aproximação dos estudantes às escalas sociais vividas no processo de uso e ocupação dos Cerrados, nas últimas décadas do século XX e no início do século XXI.

A respeito da pesquisa-ação desenvolvida, podem-se afirmar três perspectivas pontuais:

- A pesquisa com representações sociais esteve conectada com as habilidades e competências do ensino médio para se alcançar a 
formação de conceitos e, se possível, a formação cidadã em relação às novas (re)territorialidades nos Cerrados do oeste da Bahia.

- O documentário foi um importante instrumento audiovisual tanto para a motivação como para o próprio desenvolvimento da pesquisa-ação, uma vez que possibilitou a ampliação e contextualização das ebulições humanas nas áreas dos Cerrados brasileiros.

- A construção de cenários representativos do processo de uso e ocupação (histórico) revelou um importante instrumento para a (re)significação do processo de ensino e aprendizagem na Geografia Escolar, sobretudo para (re)significações das representações sociais hegemônicas imbuídas no espaço escolar pela mídia de massa.

Acredita-se que essa pesquisa-ação foi de fundamental importância para desconstruir as práticas cristalizadas de ensino e aprendizagem em Geografia no espaço escolar. Para Castrogiovanni (2011, p. 176), o nosso "movimento pedagógico deve ser uma constante pesquisa-ação. Uma desconstrução motivada pelos princípios da pesquisa-ação”, que foi iniciada na formação inicial (estágio), uma vez que tanto os docentes em formação e atuantes, como os discentes, desenvolveram sensibilidade ambiental em relação às paisagens dos Cerrados baianos, ou melhor, do oeste da Bahia.

\section{Notas}

1. Essa pesquisa foi desenvolvida sob a nossa orientação, na disciplina "Didática e Práxis Pedagógica: Estágio IV”, curso de licenciatura em Geografia do Instituto de Ciências Ambientais e Desenvolvimento Sustentável - ICADS/UFBA, durante o ano letivo de 2011.1 e 2011.2. Foi realizada pela estudante Iracema Souza de Oliveira, que cedeu as imagens para elaboração deste artigo.

2. Utilizou-se o conceito "Cerrados", no plural, pela compreensão de que o mesmo é detentor tanto de uma rica biodiversidade como de uma diversidade social, econômica, cultural e política ímpar. Portanto, tratá-lo no singular seria simplificá-lo à luz da ciência geográfica contemporânea.

3. No dia 4 de março de 1985, foi assinado, no Japão, o contrato do PRODECER II. Com isso, a Cooperativa Agrícola de Cotia começa a procurar terras na região de Barreiras, na Bahia (IBASE, 1984, p. 4).

4. As franjas dos Cerrados são áreas de remanescentes das paisagens naturais desse "domínio da natureza” (Aziz Nacib Ab’Saber, 2003), lugares onde há uma forte presença das populações tradicionais, que estabelecem sua (re)existência ao longo do processo de uso e ocupação dos chamados "sertões brasileiros". 
5. Sobre o conceito de "sertão" na ciência geográfica, ler mais em Almeida (2008) e Paula (2009).

Obs.: Agradeço a leitura atenta realizada pelo colega Marcos Mondardo.

\section{Referências}

AB'SABER, A. N. Os domínios de natureza no Brasil: potencialidades paisagísticas. São Paulo: Ateliê Editorial, 2003.

ALBAGLI, S. Geopolítica da biodiversidade. Brasília: Instituto Brasileiro do Meio Ambiente e dos Recursos Naturais Renováveis, 1998.

ALMEIDA, G. de. Cultura Ecológica e biodiversidade. Mercator: revista de Geografia da UFC, Fortaleza-CE, ano 1, n. 3, p. 71-82, jun./jul. 2003.

ALMEIDA, G. de. (Org.). Tantos Cerrados: múltiplas abordagens sobre a biogeodiversidade e singularidade cultural. Goiânia: Ed. Vieira, 2005.

ALMEIDA, G. de. Uma leitura etnogeográfica do Brasil sertanejo. In: SERPA, A. (Org.). Espaços culturais: vivências, imaginações e representações. Salvador: EDUFBA, 2008. p. 294-313.

BOURDIEU, P. A TV precisa de um contrapoder. Jornal do Brasil, Caderno Ideias, 11/09/2000.

BRASIL. Ministério do Meio Ambiente: <http://siscom.ibama.gov.br/monitorabiomas/cerrado/.>. Acesso em: 25 maio 2012.

CASTROGIOVANNI, A. C. Diferentes conceitos nas complexas práticas de ensino em Geografia. In: TONINI, I. M. et al. O ensino da Geografia e suas composições curriculares. Porto Alegre: UFRGS, 2011.

CAVALCANTI, L. S. A Geografia Escolar e a sociedade brasileira contemporânea. In: TONINI, I. M. (Org.). O ensino da Geografia e suas composições curriculares. Porto Alegre: UFRGS, 1998.

CLAVAL, P. Uma, ou algumas, abordagem(ns) cultural(is) na Geografia Humana? In: SERPA, A. (Org.). Espaços culturais: vivências, imaginações e representações. Salvador: EDUFBA, 2008.

CORRÊA, M. M. S. da. Naturalistas e viajantes estrangeiros em Goiás (1800-1850). In: RIBEIRO, P. R.; CHAUL, N. F. (Orgs.). Goiás: identidade, paisagem e tradição. Goiânia: Ed. UCG, 2001.

DIEGUES, A. C. S. A. O mito moderno da natureza intocada. São Paulo: Ed. Hucitec, 1996.

DUARTE, L. M. G.; THEODORO, S. H. (Orgs.). Dilema dos Cerrados: entre o ecologicamente (in)correto e o socialmente (in)justo. Rio de Janeiro: Garamond, 2002.

HAESBAERT, R. Gaúchos no Nordeste: modernidade, des-territorialização e identidade. Tese (Doutorado) - FFLCH/Universidade de São Paulo, São Paulo, 1995. 
INTITUTO BRASILEIRO DE ANÁLISES SOCIAIS E ECONÔMICAS (IBASE). $O$ capital japonês no Brasil. Rio de Janeiro: IBASE, 1984.

KOZEL, S. As representações no geográfico. In: MENDONÇA, F. e KOZEL, S. Elementos de epistemologia da Geografia contemporânea. Curitiba: Editora da UFPR, 2002.

KOZEL, S. Representação e Ensino: aguçando o olhar geográfico para os aspectos didático-pedagógicos. In: SERPA, A. (Org.). Espaços culturais: vivências, imaginações e representações. Salvador: EDUFBA, 2008.

LEFEBVRE, H. A produção do espaço. Trad. Doralice Barros Pereira e Sérgio Martins (do original: La production de l'espace; primeira versão: fev.2006). 4. ed. Paris: Éditions Anthropos, 2000.

MASSEY, D. Pelo espaço - uma nova política da espacialidade. Rio de Janeiro: Bertrand Brasil, 2008.

MORAES, G. R. A chave do tamanho abre o conhecimento do espaço geográfico. 2006. Dissertação (Mestrado em Geografia) - Instituto de Geociências da Universidade Federal do Rio Grande do Sul, Porto Alegre, 2006. 138 p.

MOREIRA, R. Pensar e ser em Geografia. São Paulo: Contexto, 2010.

MOSCOVICI, S. Representações sociais: investigações em psicologia social. Editado em inglês por Gerard Duveen e traduzido por Pedrinho A. Guareschi. Petrópolis-RJ: Vozes, 2003.

OLIVEIRA, I. Relatório de Estágio Supervisionado em Geografia Escolar. Universidade Federal da Bahia. ICADS/UFBA, 2011.

PAULA, A. M. N. R. de. Travessias - movimentos migratórios em comunidades rurais no sertão do norte de Minas Gerais. Tese (Doutorado) - Universidade Federal de Uberlândia/UFU, Uberlândia, 2009.

RIGONATO, V. D. A dimensão sociocultural das paisagens do Cerrado goiano: o distrito de Vila Borba. In: ALMEIDA, M. G. (Org.). Tantos Cerrados. Goiânia: Ed.Vieira, 2005. p. 49-71.

ROCHA, G. O. R. da; AMORAS, I. C. R. O ensino de Geografia e a construção de representações sociais sobre a Amazônia. Revista Terra Livre, n. 26, v. 1, p. 143164 .

SANTOS, M. Manifesto dos geógrafos. Revista Território, Rio de Janeiro, ano V, n. 9, p.103-109, jul./dez. 2000. Disponível em: <www.revistaterritório.com.br/ pdf/09_7_santos.pdf>. Acesso em: 15/11/2012.

SOCIEDADE BRASILEIRA PARA O PROGRESSO DA CIÊNCIA (SBPC), Regional de Goiás. Documentário: Cerrado: afinal o que é? E para que serve o Cerrado? Goiânia (GO), UFG, 2008. DVD com duração aproximada de 17 minutos.

SERPA, A. O espaço público na cidade contemporânea. São Paulo: Contexto, 2007.

SERPA, A. (Org.). Espaços culturais: vivências, imaginações e representações. Salvador: EDUFBA, 2008. 
SOUZA, J. G.; KATUTA, Â. M. Geografia e conhecimentos cartográficos. São Paulo: Editora UNESP, 2001.

STRAFORINI, R. Ensinar Geografia: o desafio da totalidade-mundo nas séries iniciais. São Paulo: Annablume, 2004.

THIOLLENT, M. Metodologia da pesquisa-ação. São Paulo: Cortez, 2008.

Valney Dias Rigonato - Licenciado em Geografia pela Universidade Federal de Goiás - Mestre em Geografia pela mesma universidade - Professor do curso de Geografia na Universidade Federal da Bahia.

Recebido para publicação em 21 de março de 2013

Aceito para publicação em 29 de junho de 2013 